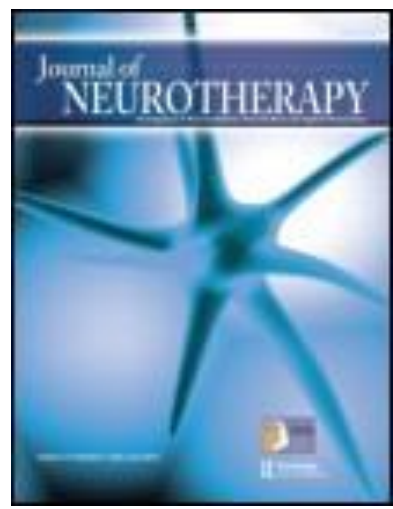

Journal of Neurotherapy: Investigations in Neuromodulation, Neurofeedback and Applied Neuroscience

\title{
Cognitive Function During Vagus Nerve Stimulation for Treatment-Refractory Epilepsy: A Pilot Study Using the Critical Flicker Fusion Test
}

\author{
Kanu Achinivu ${ }^{a}$, Ekkehart Staufenberg ${ }^{b}$, Christine Cull ${ }^{c}$, Andrea E. Cavanna ${ }^{\text {ad }}$ \& Howard Ring ${ }^{e}$ \\ a Department of Neuropsychiatry, University of Birmingham and BSMHFT, Birmingham, United Kingdom \\ b David Lewis Centre for Epilepsy, Cheshire, United Kingdom \\ C Mid Anglia Community Health NHS Trust, Haverhill, Suffolk, United Kingdom \\ d Sobell Department of Motor Neuroscience and Movement Disorders, Institute of Neurology, UCL, London, \\ United Kingdom \\ e Developmental Psychiatry Section, University of Cambridge, Cambridge, United Kingdom \\ Published online: 02 Mar 2012.
}

To cite this article: Kanu Achinivu, Ekkehart Staufenberg, Christine Cull, Andrea E. Cavanna \& Howard Ring (2012) Cognitive Function During Vagus Nerve Stimulation for Treatment-Refractory Epilepsy: A Pilot Study Using the Critical Flicker Fusion Test, Journal of Neurotherapy: Investigations in Neuromodulation, Neurofeedback and Applied Neuroscience, 16:1, 32-36, DOI: $\underline{10.1080 / 10874208.2012 .650097}$

To link to this article: http://dx.doi.org/10.1080/10874208.2012.650097

\section{PLEASE SCROLL DOWN FOR ARTICLE}

(c) International Society for Neurofeedback and Research (ISNR), all rights reserved. This article (the "Article") may be accessed online from ISNR at no charge. The Article may be viewed online, stored in electronic or physical form, or archived for research, teaching, and private study purposes. The Article may be archived in public libraries or university libraries at the direction of said public library or university library. Any other reproduction of the Article for redistribution, sale, resale, loan, sublicensing, systematic supply, or other distribution, including both physical and electronic reproduction for such purposes, is expressly forbidden. Preparing or reproducing derivative works of this article is expressly forbidden. ISNR makes no representation or warranty as to the accuracy or completeness of any content in the Article. From 1995 to 2013 the Journal of Neurotherapy was the official publication of ISNR (www. Isnr.org); on April 27, 2016 ISNR acquired the journal from Taylor \& Francis Group, LLC. In 2014, ISNR established its official open-access journal NeuroRegulation (ISSN: 2373-0587; www.neuroregulation.org).
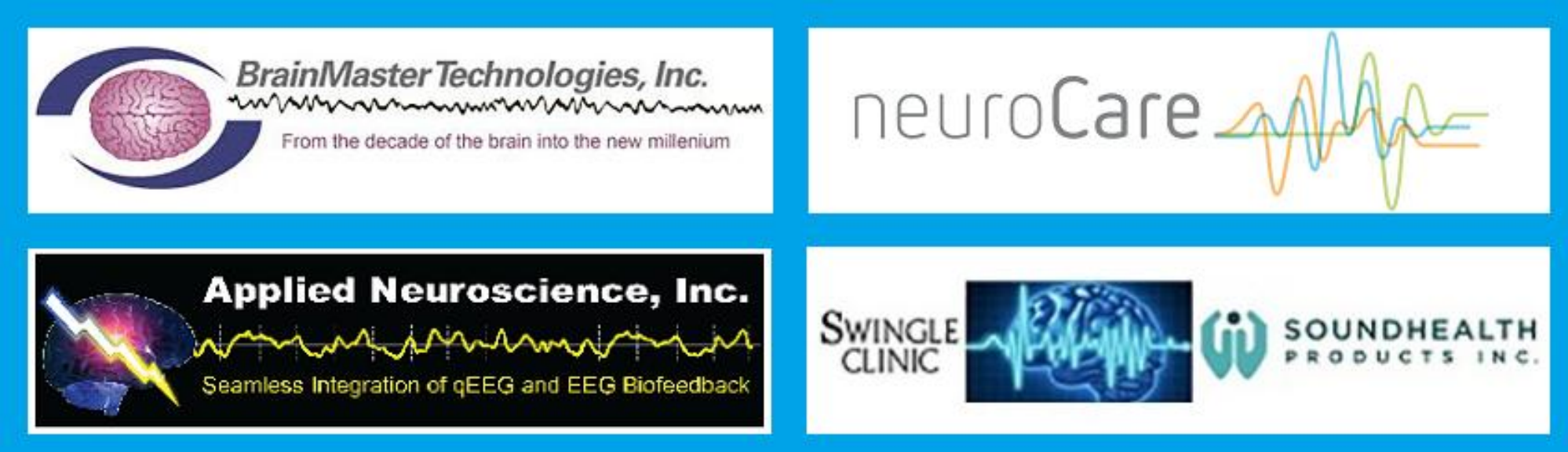


\title{
COGNITIVE FUNCTION DURING VAGUS NERVE STIMULATION FOR TREATMENT-REFRACTORY EPILEPSY: A PILOT STUDY USING THE CRITICAL FLICKER FUSION TEST
}

\author{
Kanu Achinivu', Ekkehart Staufenberg ${ }^{2}$, Christine Cull ${ }^{3}$, Andrea E. Cavanna ${ }^{1,4}$, Howard Ring ${ }^{5}$ \\ ${ }^{1}$ Department of Neuropsychiatry, University of Birmingham and BSMHFT, Birmingham, \\ United Kingdom \\ ${ }^{2}$ David Lewis Centre for Epilepsy, Cheshire, United Kingdom \\ ${ }^{3}$ Mid Anglia Community Health NHS Trust, Haverhill, Suffolk, United Kingdom \\ ${ }^{4}$ Sobell Department of Motor Neuroscience and Movement Disorders, Institute of Neurology, \\ UCL, London, United Kingdom \\ ${ }^{5}$ Developmental Psychiatry Section, University of Cambridge, Cambridge, United Kingdom
}

This pilot study assessed neuro-cognitive functioning in 7 adults treated with Vagus Nerve Stimulation (VNS) for refractory epilepsy over a 12-month period. All patients were assessed using the Critical Flicker Fusion (CFF) test, a sensitive measure of the ability of the central nervous system to discriminate items of sensory information, along with a standardized battery of neuropsychological and behavioral measures. Reduction in seizure frequency and psychiatric ratings was accompanied by a selective but significant $(p<.05)$ improvement in CFF performance. These findings suggest that the CFF test could be a useful indicator of improvement in neurocognitive functioning during VNS.

\section{INTRODUCTION}

Chronic epilepsy has been shown to contribute to general cognitive decline in patients with intractable epilepsy compared to patients with controlled seizures or a shorter history of epilepsy (Jokeit \& Ebner, 1999). Improvement in cognitive functioning in patients with epilepsy has important implications in their activities of daily living and health-related quality of life. Although most people with epilepsy have their seizures controlled by antiepileptic medications, $20 \%$ to $30 \%$ of patients who are ineligible for epilepsy surgery continue to have seizures (Devinsky, 1999), and a subgroup of these might benefit from neuromodulation with Vagus Nerve Stimulation (VNS; The Vagus Nerve Stimulation Study Group, 1995). Since the development of VNS for treatmentrefractory epilepsy, some clinical observations reported a possible cognition-enhancing effect (Clarke, Upton, Griffin, Fitzpatrick, \& DeNardis, 1997; Clarke, Upton, Griffin, \& Hudoba, 1991; Martin, Denburg, Tranel, Granner, \& Bechara, 2004; Sackeim et al., 2001; Scherrmann, Hoppe, Kral, Schramm, \& Elger, 2001), whereas others disputed such an effect (Danielsson, Viggedal, Gillberg, \& Olsson, 2008; Dodrill \& Morris, 2001; Hallböök et al., 2005; Hoppe, Helmstaedter, Scherrmann, \& Elger, 2001). Different methodologies of assessing cognitive functioning have been employed, most of which lack sensitivity to record slight changes in alertness. In this pilot study, we set out to explore the neurocognitive effects of VNS in patients with treatment-refractory epilepsy using the Critical Flicker Fusion (CFF) test, a neuropsychological research tool that measures the cognitive integrative capacity of the central nervous system (Curran, 1997; Hindmarch, 1975).

Received 25 September 2011; accepted 30 November 2011.

Address correspondence to Andrea E. Cavanna, MD, PhD, Department of Neuropsychiatry, The Barberry National Centre for Mental Health, Birmingham B152FG, United Kingdom. E-mail: A.Cavanna@ion.ucl.ac.uk 


\section{METHODS}

\section{Study Design}

Consecutive adult patients with treatmentresistant epilepsy referred to the Epilepsy VNS Implantation Programme at two regional University Hospitals in England were approached by their clinical teams with information about the study. Seven patients entered a pilot study with a prospective design over a 12-month period. Observations were recorded at baseline (prior to switching on) and at 12 months. Throughout their participation in the study the participants were asked to keep a seizure diary. The study protocol enabled the clinical team to adjust antiepileptic drug therapy if this was indicated during the follow-up period. The stimulation protocols for the VNS NeuroCybernetic Prosthesis system were followed by the treating physicians according to standard clinical practice. The research team was blind to the stimulation parameters for each participant. Written informed consent was obtained from all participants. The study was approved by the local Research Ethics Committee.

\section{Assessment Measures}

All participants completed the following self-rated behavioral measures:

1. The Hospital Anxiety and Depression Scale, a brief self-report instrument validated in hospital and community patients for the assessment of anxiety and depression symptoms in patients with chronic physical illnesses.

2. The Quality of Life in Epilepsy Scale, a validated 10-item self-report questionnaire that assesses health-related quality of life in people with epilepsy.

All participants were also instructed to complete the following automated neuropsychological tests:

1. The Raven's Standard Progressive Matrices (SPM), which assess concept formation, set-shifting and the ability to identify logical patterns in nonverbal stimuli including spatial, design, and numerical relationships.

2. The Cognitrone, a test of sustained attention and concentration through the comparison of figures to identify similarities and congruence.

3. The Continuous Visual Recognition Task (CVRT), a memory test that involves encoding and recognition of recurring visual stimuli (pictures, words, and numbers).

The CFF test, a computer-assisted cognitive test in which participants are required to identify the moment (measured as the frequency in cycles per second) when light from a small standardized source that is flickering at a steadily increasing rate (from slow to very fast) is perceived to have changed from flickering to constant illumination. This rate is described as the "Fusion" frequency. The process is controlled by a computer, and the participant is asked to confirm a change in perception by pressing a button on the device. The median values of the critical frequencies obtained in repeated trials of increasing modes are recorded as the Fusion Frequency. The CFF assesses an aspect of the cognitive integrative capacity of the central nervous system, specifically its ability to discriminate items of sensory information (Curran, 1997; Hindmarch, 1975).

\section{Statistical Analysis}

Data are presented as mean (standard deviation) values. Statistical comparisons were performed with the Wilcoxon signed rank test. The level of significance was set at $p<.05$ (two-tailed).

\section{RESULTS}

The demographic and clinical characteristics of the patients who took part in this study are reported in Table 1. Following the switch on of stimulators, the group as a whole showed a significant improvement in seizure frequency $(p=.05)$, with three participants reporting a less than $50 \%$ reduction in overall seizure frequency at 12 months (Table 1). VNS treatment also resulted in a significant improvement in 
TABLE 1. Demographic and Clinical Characteristics of the Participants

\begin{tabular}{|c|c|c|c|c|c|c|c|c|c|}
\hline Participant & Sex & $\begin{array}{l}\text { Age at } \\
\text { study } \\
\text { onset }\end{array}$ & $\begin{array}{l}\text { Education } \\
\text { years }\end{array}$ & $\begin{array}{l}\text { Previous } \\
\text { diagnosis } \\
\text { of LD }\end{array}$ & $\begin{array}{l}\text { Duration } \\
\text { of epilepsy }\end{array}$ & $\begin{array}{l}\text { No of } \\
\text { AEDs }\end{array}$ & $\begin{array}{l}\text { Average } \\
\text { no. of } \\
\text { seizures/month } \\
\text { at baseline }\end{array}$ & $\begin{array}{l}\text { Average } \\
\text { no. of } \\
\text { seizures/month } \\
\text { at } 12 \text { months }\end{array}$ & $\begin{array}{l}\text { Change in } \\
\text { seizure } \\
\text { frequency } \\
\text { at } 12 \text { months }\end{array}$ \\
\hline 1 & $M$ & 51 & 13 & No & 49 & 4 & 6 & 4 & $\downarrow(33 \%)$ \\
\hline 2 & $\mathrm{~F}$ & 20 & 12 & No & 6 & 3 & 8 & 2 & $\downarrow(75 \%)$ \\
\hline 3 & $\mathrm{~F}$ & 35 & 12 & No & 34 & 2 & 3 & 2 & $\downarrow(33.3 \%)$ \\
\hline 4 & $M$ & 49 & 10 & Yes & 43 & 3 & 6 & 8 & $\uparrow(33.3 \%)$ \\
\hline 5 & $\mathrm{~F}$ & 41 & 12 & No & 33 & 2 & 18 & 15 & $\downarrow(5 \%)$ \\
\hline 6 & $M$ & 25 & 18 & No & 23 & 3 & 300 & 10 & $\downarrow(97 \%)$ \\
\hline 7 & $M$ & 54 & 10 & No & 48 & 3 & 40 & 1 & $\downarrow(97 \%)$ \\
\hline
\end{tabular}

Note. $\mathrm{LD}=$ learning disability; AEDs = antiepileptic drugs.

TABLE 2. Results of Neuropsychological Tests at Baseline and after 12 Months of Vagus Nerve Stimulation Treatment

\begin{tabular}{lccl}
\hline Test & Baseline & 12 Months & Significance $^{a}$ \\
\hline SPM & $77.6(12.2)$ & $80.9(14.3)$ & $n s$ \\
Cognitrone & $4.1(2.0)$ & $4.2(1.7)$ & $n s$ \\
CRVT & $43.6(13.7)$ & $44.4(21.8)$ & $n s$ \\
CFF test & $34.3(4.9)$ & $36.2(3.0)$ & $p=.042$ \\
\hline
\end{tabular}

Note. SPM = Raven's Standard Progressive Matrices; CRVT = Continuous Visual Recognition Task; CFF $=$ Critical Flicker Fusion.

${ }^{a}$ Wilcoxon Signed Rank Test.

the "seizure worry" and "memory" domains of the Quality of Life in Epilepsy Scale (both $p<.05)$ and a trend toward reduction in the severity of anxiety symptoms measured by the Hospital Anxiety and Depression Scale at 12 months $(p=.107)$.

The results of the neuropsychological tests at baseline and after 12 months of VNS treatment are presented in Table 2. Data at the 12-month follow-up assessment showed a trend toward improvement in visual recognition and logical thinking (SPM), attention and concentration (Cognitrone), and memory (CRVT). However, none of these changes were statistically significant. On the other hand, all patients showed improvement in CFF following 12 months of treatment with VNS compared to baseline and across the group this improvement was significant at $p<.05$.

\section{DISCUSSION}

This prospective pilot study suggests that the CFF can be a useful and sensitive test in detecting subtle cognitive enhancement in patients with refractory epilepsy successfully treated with VNS. The 12-month results of CFF fusion rate imply that VNS may significantly increase central nervous system arousal and further supports recent evidence of such an effect in adults with probable Alzheimer's dementia (Merrill et al., 2006).

The ability of the CFF test to detect small changes in central nervous system integrative capacity makes it an interesting instrument for measuring the level of cortical activation/ arousal, which can be an indicator of improvement in neurocognitive functioning. The overall results of the other neuropsychological tests used in the present study showed nonsignificant improvements in the domains of memory and learning, attention and concentration, and nonverbal intelligence in the majority of our participants. These findings support the results of the CFF, although the other tests did not appear to be as sensitive as the CFF in detecting small differences in cognitive performance.

In addition to its effects on neurocognitive functioning, VNS is known to improve other health outcomes. Our study demonstrated an overall reduction in seizure frequency across the group of around $80 \%$ from baseline to 12 months. This value might appear quite large compared to what other studies have demonstrated (Ben-Menachem et al., 1994; Handforth et al., 1998); however, it must be noted that two participants demonstrated a greater than $90 \%$ reduction in seizure frequency, with the rest of the group showing a modest 20\% reduction. No patient within our study group 
became seizure free. This seems to suggest that the improvements in cognition that our study identified stem from an independent effect not related to the antiepileptic properties of VNS. With respect to a possible effect of antiepileptic medication change, although changes to antiepileptic medications by the treating clinical team were allowed throughout the duration of study, participants remained on the same medications and dose throughout the study period. Finally, our pilot study supports the observations of Rush et al. (2000) that VNS might have an antianxiety effect.

A number of limitations in the design of our pilot study should be considered. The small sample size led to a reduced statistical power; however, this effect was reduced by employing a within-subject design. It is important to note that this is a pilot study and the observed differences at 12 months compared to baseline will guide researchers in designing future studies. Participants were consecutive patients referred from regional treatment centers to the researchers. As no random selection was carried out, the characteristics of the sample may not be reflective of the general population with intractable epilepsy; hence caution is needed when generalizing these results to other patient populations.

Subjective factors are also likely to have an effect on the overall results reported here. During the various phases of the study, the motivation to perform well is likely to have varied both between and within individuals. Although all participants were instructed to complete the neuropsychological tasks as quickly and accurately as possible, they may not have felt fully motivated at all times to comply with this.

Although our pilot study makes the first attempt in clarifying the relationship between VNS treatment for epilepsy and cognitive function using the CFF, further research is warranted in the form of more systematic studies, employing larger sample sizes and randomization methods. Future work is required not only to replicate evidence of the cognitive effects we detected using the CFF but also to further clarify whether such benefits are a direct physiological consequence of VNS or secondary result of changes in affective state or epilepsy severity.

\section{REFERENCES}

Ben-Menachem, E., Mañon-Espaillat, R., Ristanovic, R., Wilder, B. J., Stefan, H., Mirza, W., ... Wernicke, J. F. (1994). Vagus nerve stimulation for the treatment of partial seizures: 1. A controlled study of effect on seizures. Epilepsia, 35, 616-626.

Clarke, B. M., Upton, A. R. M., Griffin, H., Fitzpatrick, D., \& DeNardis, M. (1997). Chronic stimulation of the left vagus nerve: Cognitive motor effects. Canadian Journal of Neurological Sciences, 24, 226-229.

Clarke, B. M., Upton, A., Griffin, H., \& Hudoba, P. (1991). Balance and cognitive impairment in two epileptic patients before and after vagal nerve stimulation. Pacing and Clinical Electrophysiology, 14, 77-85.

Curran, S. (1997). Critical flicker fusion techniques in psychopharmacology. In I. Hindmarch \& P. D. Stonier (Eds.), Human psychopharmacology: Methods and measures (Vol. 3, pp. 21-38). New York, NY: Wiley.

Danielsson, S., Viggedal, G., Gillberg, C., \& Olsson, I. (2008). Lack of effects of vagus nerve stimulation on drug-resistant epilepsy in eight pediatric patients with autism spectrum disorders: A prospective 2-year follow-up study. Epilepsy \& Behavior, 12, 298-304.

Devinsky, O. (1999). Patients with refractory seizures. New England Journal of Medicine, 340, 1565-1570.

Dodrill, C. B., \& Morris, G. L. (2001). Effects of vagal nerve stimulation on cognition and quality of life in epilepsy. Epilepsy \& Behavior, 2, 46-53.

Hallböök, T., Lundgren, J., Stjernqvist, K., Blennow, G., Strömblad, L. G., \& Rosén, I. (2005). Vagus nerve stimulation in 15 children with therapy resistant epilepsy; its impact on cognition, quality of life, behaviour and mood. Seizure, 14, 504-513.

Handforth, A., DeGiorgio, C. M., Schachter, S. C., Uthman, B. M., Naritoku, D. K., Tecoma, E. S., ... Wheless, J. W. (1998). Vagus nerve stimulation therapy for partialonset seizures: A randomized active-control trial. Neurology, 51, 48-55. 
Hindmarch, I. (1975). A 1, 4-Benzodiazepine, temazepam ( $\mathrm{K}$ 3917), its effect on some psychological parameters of sleep and behaviour. Arzneim-Forsch (Drug Res), 25, 1836-1839.

Hoppe, C., Helmstaedter, C., Scherrmann, J., \& Elger, C. E. (2001). No evidence for cognitive side effects after 6 months of vagus nerve stimulation in epilepsy patients. Epilepsy \& Behavior, 2, 351-356.

Jokeit, H., \& Ebner, A. (1999). Long term effects of refractory temporal lobe epilepsy on cognitive abilities: A cross sectional study. Journal of Neurology, Neurosurgery, and Psychiatry, 67, 44-50.

Martin, C. O., Denburg, N. L., Tranel, D., Granner, M. A., \& Bechara, A. (2004). The effects of vagus nerve stimulation on decisionmaking. Cortex, 40, 605-612.

Merrill, C. A., Jonsson, M. A., Minthon, L., Ejnell, H., C-son Silander, H., Blennow, K., ... Sjögren, M. J. (2006). Vagus nerve stimulation in patients with Alzheimer's disease: Additional follow-up results of a pilot study through 1 year. Journal of Clinical Psychiatry, 67, 1171-1178.

Rush, A. J., George, M. S., Sackeim, H. A., Marangell, L. B., Husain, M. M., Giller, C., ... Goodman, R. (2000). Vagus nerve stimulation (VNS) for treatment-resistant depressions: A multicenter study. Biological Psychiatry, 47, 276-286.

Sackeim, H. A., Keilp, J. G., Rush, A. J., George, M. S., Marangell, L. B., Dormer, D. S., ... Zboyan, H. (2001). The effects of vagus nerve stimulation on cognitive performance in patients with treatment-resistant depression. Neuropsychiatry, Neuropsychology, and Behavioral Neurology, 14, 53-62.

Scherrmann, J., Hoppe, C., Kral, T., Schramm, J., \& Elger, C. E. (2001). Vagus nerve stimulation: Clinical experience in a large patient series. Journal of Clinical Neurophysiology, 18, 408-414.

The Vagus Nerve Stimulation Study Group. (1995). A randomized controlled trial of chronic vagus nerve stimulation for treatment of medically intractable seizures. Neurology, 45, 224-230. 